\title{
ReSEnhas
}

\section{DILEMAS E ESCOLHAS DO SISTEMA DE SAÚDE: ECONOMIA DA SAÚDE OU SAÚDE DA ECONOMIA?}

\author{
Marcos Bosi Ferraz \\ Medbook, Rio de Janeiro, 2008
}

\begin{abstract}
Andrea Donatti Gallassi(*)
Andrea Donatti Gallassi*

A abordagem econômica nos estudos em saúde é bastante incipiente no Brasil, como também nos demais países em desenvolvimento. É um tema atual e que vem demonstrando relevância nas diversas esferas que compõem o setor saúde, dada a necessidade de um melhor planejamento para a aplicação de recursos nesta área.

Estimativas de custo e avaliações econômicas apresentam vários propósitos para sua aplicação. Podem ser utilizadas na argumentação e elaboração de políticas públicas, auxiliam na criação de metas específicas que minimizem os custos; na elucidação de dados empíricos, como, por exemplo, saber se os valores arrecadados com impostos da indústria do álcool são, de fato, maiores do que os valores gastos com o tratamento de problemas relacionados ao uso indevido dessa substância; contribuem para a identificação de necessidades de pesquisas mais aprofundadas em determinado assunto e também para o refinamento, desejável, do sistema nacional de estatística, como o Departamento de Informática do SUS (DATASUS) e o Sistema de Informações sobre Orçamentos Públicos em Saúde (SIOPS) do Ministério da Saúde.

Essas questões são abordadas de forma clara e de fácil compreensão para iniciantes no tema, na obra Dilemas e Escolhas do Sistema de Saúde:

(*) Mestre e doutoranda pela Faculdade de Medicina da Universidade de São Paulo (FMUSP). E-mail: <andreag@usp.br>. Recebido em 27.1.09.
\end{abstract}


Economia da Saúde ou Saúde da Economia, de Marcos Bosi Ferraz. A publicação é composta por 16 capítulos que, aos poucos, vão introduzindo ao leitor os principais conceitos relacionados com o tema economia da saúde.

O autor inicia o livro trazendo uma reflexão acerca das diferenciações entre a natureza das ciências biológicas, exatas e humanas. Especificamente com relação às ciências biológicas ou ciências da saúde, ele as caracteriza como sendo compostas por forças que transitam entre as ciências exatas e as humanas, na medida em que:

trazem consigo o desejo de um mínimo de incerteza (força em direção às ciências exatas) e um máximo de respeito às preferências individuais, assumindo que o paciente ou cidadão esteja minimamente orientado quanto à condição de discussão e às consequências de possíveis decisões (força em direção às ciências humanas). (p. 5)

O título do capítulo 2 - Tendências recentes que influenciam os sistemas de saúde no mundo - suscita a ideia de que serão abordadas as principais influências que os sistemas de saúde no mundo, com esperada ênfase para o caso brasileiro, sofreram durante suas concepções. Porém, o que ocorre é a contextualização do momento de inovação tecnológica que o mundo está vivendo e, consequentemente, o setor da saúde e seu impacto econômico frente às novas necessidades de saúde apresentadas. É neste momento que o autor introduz o conceito de economia da saúde, como:

sendo o estudo de como indivíduos e sociedades exercem a opção de escolha na alocação dos escassos recursos destinados à área da saúde entre as alternativas que competem para seu uso, e como estes escassos recursos são distribuídos entre membros da sociedade. (p. 16)

No capítulo 3, o autor faz uma breve relação entre o percentual do PIB investido em saúde em países desenvolvidos, em comparação aos em desenvolvimento, e descreve a diferença existente entre os valores praticados atualmente pelo Brasil com relação aos EUA. Também aponta que o aumento desse investimento em saúde observado ao longo dos últimos anos no Brasil, não representa a eficiência técnica esperada, já que os valores de alguns indicadores, como mortalidade infantil, são equivalentes aos apresentados por países desenvolvidos 40 ou 50 anos atrás.

O custo de oportunidade, importante conceito praticado na Economia da Saúde, é apresentado ao leitor no capítulo 4. De forma resumida, este conceito aponta a perda, inevitável, atribuída ao indivíduo ou, nesse caso, ao sistema de saúde quando se faz escolhas. O custo de oportunidade deixa clara a importância de evitar o desperdício e a má alocação de recurso já que, uma vez investido em uma determinada atividade, esse recurso não estará mais disponível para ser utilizado em outro fim. O autor introduz sutilmente outros elementos e conceitos que também compõem o universo da economia da saúde, como PIB, inflação e renda da população brasileira. Bosi trata também sobre como esses conceitos se relacionam e impactam o setor saúde. 
No capítulo 5, o autor apresenta uma série de estimativas e projeções, considerando o intervalo entre os anos 2005 a 2025, variando os valores do $\mathrm{PIB}$, da inflação média geral e inflação média de gasto em saúde e como e quanto essa variação interfere no investimento das famílias em saúde, de acordo com cada cenário. O que chama a atenção nessas estimativas é o fato das análises serem realizadas tendo como questão a ser respondida a possibilidade ou não das famílias pagarem o sistema supletivo de assistência à saúde.

Os capítulos 6 e 7 apontam um aspecto fundamental, que está diretamente relacionado com o bom ou o mau desempenho do sistema de saúde, que são os sistemas adjacentes a ele, como educação, saneamento básico, educação, habitação, segurança, transporte etc. Outro ponto importante que o autor aborda nestes capítulos, e na obra como um todo, trata da importância do reconhecimento, por parte dos cidadãos e dirigentes, de que os recursos são escassos e que, por isso, devem ser aplicados com critério e planejamento.

No capítulo 8, Bosi retoma a problemática da escassez de recursos a qual o setor da saúde está condicionado e, em função disso, alerta para a necessidade da busca pela eficiência técnica, produtiva e de alocação desses recursos. Esses são aspectos tratados no capítulo seguinte (9), com ênfase na difícil tarefa de se tomar decisões buscando sempre a efetividade na atenção à saúde.

O capítulo 10 traça o panorama da educação médica no Brasil, com pertinentes críticas ao boom de faculdades de medicina e sua questionável qualidade. Chama a atenção nesse capítulo, o fato do autor limitar a caracterização das equipes de saúde e da eficiência da atenção somente pela perspectiva unidisciplinar, ou seja, somente pela existência ou não da força de trabalho médica.

No capítulo 11, Bosi faz um paralelo entre as inovações tecnológicas disponíveis hoje para o setor da saúde e os custos para sua incorporação, ou seja, a necessidade de haver um processo de avaliação, de modo que inclua os custos e os benefícios da utilização destas tecnologias. O conceito e a aplicabilidade da avaliação econômica são melhor explorados no capítulo seguinte (12), onde são introduzidas ao leitor as "palavras mágicas" da economia da saúde, como avaliação de custo-efetividade, custo-benefício, custo-utilidade, $Q A L Y s$, dentre outras.

De forma bastante sucinta e superficial, o autor propõe uma reflexão, no capítulo 13 , sobre o dilema existente no sistema de saúde com relação aos custos que envolvem intervenções preventivas e curativas e da dificuldade, diante disso, de se fazer escolhas sobre como, quanto e em que investir e quais os resultados almejados. 
O capítulo 14 separa em três grandes blocos as principais necessidades do sistema de saúde, tendo como pano de fundo a utilização de recursos, o aumento de custos e a sustentabilidade do sistema. São eles:

1. Definição de prioridades em termos de atenção à saúde (para melhor orientar as escolhas); 2. Cuidar e valorizar as necessidades do hoje, mas não deixar de planejar e construir a médio e a longo prazo; 3. Procurar compulsivamente e identificar a ineficiência na utilização dos escassos recursos e reduzi-la tanto quanto e o mais precocemente possível. (p.128)

Os capítulos 15 e 16 encerram a discussão apresentando propostas para o melhor financiamento do sistema de saúde, como, por exemplo, definir quais são as prioridades em saúde, reforçar e respeitar o controle social e fazer escolhas orientadas por evidências tidas como válidas e aplicáveis ao contexto do nosso sistema, dentre outras.

A obra de Marcos Bosi Ferraz, no geral, é feliz por convidar o leitor para o debate sobre um elemento fundamental à viabilidade de qualquer sistema de saúde: o recurso financeiro. A narrativa tem como tônica principal a escassez de recursos destinados ao setor e o reflexo disso na atenção prestada. Por outro lado, faltou explorar de forma mais contundente, e já traçando possíveis saídas, não só o fato do sistema de saúde brasileiro contar com poucos recursos, mas, primordialmente, como esses recursos são, hoje, mal aplicados. Um exemplo disso já foi observado em outros países, como em um estudo realizado na Austrália(1) $^{(1)}$ que concluiu que 0 custo social relacionado ao consumo de álcool e tabaco excedia e muito o custo social relacionado às drogas ilícitas, favorecendo assim, a atenção das políticas públicas em direção às drogas de caráter lícito, o que não ocorria até o estudo ser realizado.

Desse modo, a má alocação de recursos, muitas vezes, pode ser considerada a responsável pelas grandes mazelas observadas no cotidiano das equipes de saúde e até na própria elaboração de políticas públicas, por vezes equivocadas e altamente dispendiosas.

\section{REFERÊNCIA BIBLIOGRÁFICA}

COLLINS, D.J.; Lapsley, H.M. Estimating the economic costs of drug abuse in Australia. Canberra, Commonwealth of Australia, National Campaign Against Drug Abuse Monograph, n. 15, 1991.

(1) Collins, D. J.; Lapsley, H. M. Estimating the economic costs of drug abuse in Australia. Canberra, Commonwealth of Australia, National Campaign Against Drug Abuse Monograph, n. 15, 1991. 